timately allow the development of hemispheric-scale datasets for the last 300-500 years. These data sets will be used to document the large spatial and temporal variance that characterises the tropical (ENSO) and high latitude (e.g. PDO) atmospheric circulation features associated with interannual to decadal variability of climate over the Americas. For example, the recent ENSO reconstruction developed by Stahle et al. (1998) may be significantly enhanced by the incorporation of data from drought-resistant and $\mathrm{El}$ Niño sensitive tree-ring chronologies in Central Chile and adjacent Argentina. Similarly the development and combination of data sets to address low frequency climate variability (e.g. Villalba et al, 2001) could significantly improve understanding of phenomena such as the PDO and the relationship between PDO and ENSO phenomena. As the project continues we hope to provide data that will address these large scale issues.

Further information about participating scientists and institutions, plus the first two annual reports of activity and other information can be found on the project's web site at http://www.cricyt.edu.ar/IAl/ or through http://wdc.cricyt.edu.ar/

\section{AcKnowledgements}

We would like to thank R. Villalba, M. Morales and D.W. Stahle for providing the data in Figures 2 and 3, respectively.

\section{REFERENCES}

Acuna-Soto, R., L. Calderon Romero, and J.H. McGuire, 2000. Large epidemics of hemorrhagic fevers in Mexico 1545-1815. American Journal of Tropical Medicine and Hygiene 62(6):733-739.

Acuna-Soto, R., D.W. Stahle, M.K. Cleaveland, M.D. Therrell, in press. Megadrought and megadeath in 16th century Mexico. Emerging Infectious Diseases

Stahle, D.W., D'Arrigo, R.D., Krusic, P.J., Cleaveland M.K., Cook, E.R., Allan, R.J., Cole, J.E., Dunbar, R.B., Therrell, M.D., Gay, D.A., Moore, M.D. Stokes,. M.A., Burns, B,T, Villanueva-Diaz, J. and Thompson, L.G., 1998. Experimental dendroclimatic reconstruction of the southern oscillation. Bulletin of the American Meteorological Society, 79(10): 2137-2152.

Villalba, R., D’Arrigo, R.D., Cook, E.R., Wiles, G, and Jacoby G.C. 2001. Decadal-scale climatic variability along the extratropical western coast of the Americas: Evidences from tree-ring records. In: Inter-Hemispheric Climate Linkages, Vera Markgraf (ed.), Academic Press. pp. 155-172.

\title{
Paleoecology of Eastern Africa Mountains
}

\section{Daniel 0. Olago and Eric 0. 0dada}

Department of Geology, University of Nairobi, PO Box 30197 Nairobi, Kenya; dolago@uonbi.ac.ke, eodada@uonbi.ac.ke

Africa is a rich repository of paleoenvironmental and paleoclimatic information. It is unique in that it is the only continent that, almost symetrically, straddles the equator, and hence experiences both northern and southern hemispheric climatic influences. This, coupled with the influence of the oceans that surround it, results in an intriguing paleo-record that offers the possibility of understanding the links in climate between the high latitudes and the tropics, and inter-hemispheric teleconnections. Sedimentary records from lakes, swamps and mires, ranging in altitude from sea level to over $5,000 \mathrm{~m}$ above sea level (Kilimanjaro, Ruwenzori and Mt. Kenya, Fig.1), and extending from the northern mid-latitudes to the southern mid-latitudes, provide an array of paleo-proxies and a range of sensitivities to the regional and global climate system that are essential for the elucidation of natural climate and environmental variability in the past. Further data is particularly required in the tropical regions, where a dearth of information exists as compared to the high latitude areas. In particular, most records of the continental tropics do not extend beyond $40,000{ }^{14} \mathrm{C}-\mathrm{yr}$ BP

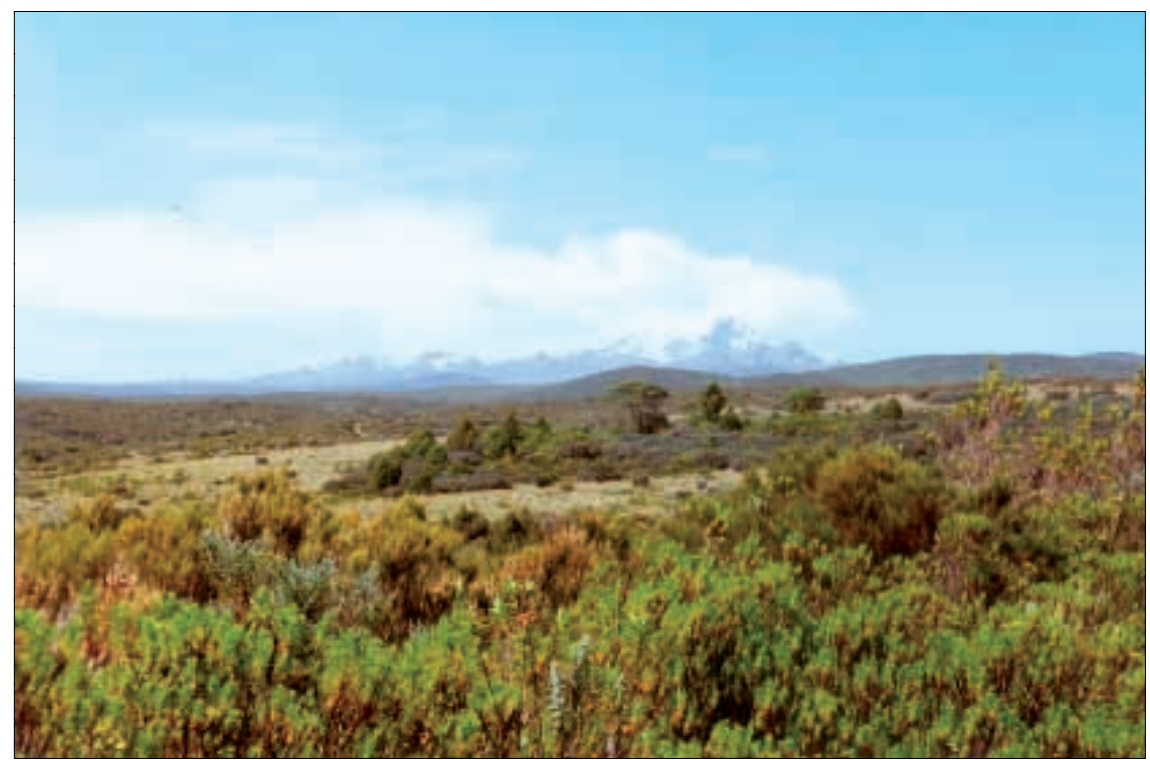

Fig. 1: View of Mount Kenya from the northern moorland.

(most tend to have records less than $\left.30,000{ }^{14} \mathrm{C}-\mathrm{yr} \mathrm{BP}\right)$. In the few cases where a long record exists, poor dating control and consequently poor age models constrain both interpretation, and correlation of events (particularly abrupt events) on local and regional scales.

\section{Modern Vegetation}

The African mountains exhibit high diversity in vegetation types due to the pronounced variations in temperature, atmospheric $\mathrm{CO}_{2}$ con- centration, solar radiation receipts, precipitation and soil moisture indices that are related to the sharp changes in altitude and the effects of topography and aspect. The vegetation is classified into three altitudinal belts, which are, with increasing altitude, the Montane Forest Belt, the Ericaceous Belt and the Afroalpine Belt (Fig. 2). Within the belts, distinct zones are recognised: thus, the Montane Forest Belt contains, in ascending order, the Montane Rain Forest Zone, the Bamboo Zone 


\section{Science Highlights}

and the Hagenia-Hypericum Zone; the Ericaceous Belt contains the Moorland Zone (Fig. 1) and the Ericaceous Zone. The Afroalpine Belt is not divided. Each belt is represented on every mountain (provided it is sufficiently high) but not all the individual zones are necessarily present. There are striking variations in the altitudes of the zone boundaries on different mountains and even on different parts of the same mountain. Some of these differences may be related to the variations in cloud cover, moisture availability and aspect. On Mount Elgon, for example, it appears that under dry sunny conditions, vegetation belts reach higher altitudes on eastern than on western slopes, resulting in considerable differences in the altitudinal ranges of vegetation between the wet and dry sides (Hamilton, 1972). Disturbance often lowers the upper limit of a species, and this is particularly apparent on Mount Elgon, where the upper boundary of the Montane Forest Belt has been lowered, thus reducing the altitudinal range of the forest species (Hamilton, 1972). The upper limit of a species range is more closely determined by temperature conditions than the lower, and extension is greatest in areas of more favourable water balance. In the case of lower altitudinal limits of species ranges, extension is encouraged by one or both of two factors: reduced competition and more favourable moisture conditions. Conditions of reduced competition occur both artificially (forest clearings, grazed land) and naturally (forest gaps, unstable soils, unfavourable microclimates). The high altitude regions $(>2,000 \mathrm{~m}$ a.s.I.) of East Africa are characterised by $\mathrm{C}_{3}$ grasses, and above $4,000 \mathrm{~m}$ grasses are exclusively $\mathrm{C}_{3}$, while lower altitude regions $(<2,000 \mathrm{~m})$ are dominated by $\mathrm{C}_{4}$ grasses but support about $10 \% \mathrm{C}_{3}$ species. It has, however, been shown that there are significant amounts of $\mathrm{C}_{4}$ grasses at altitudes up to $3,200 \mathrm{~m}$ on Mount Kenya, and in some select areas $\mathrm{C}_{4}$ grasses (e.g. Andropogon amethystinus) are found up to $4,000 \mathrm{~m}$.

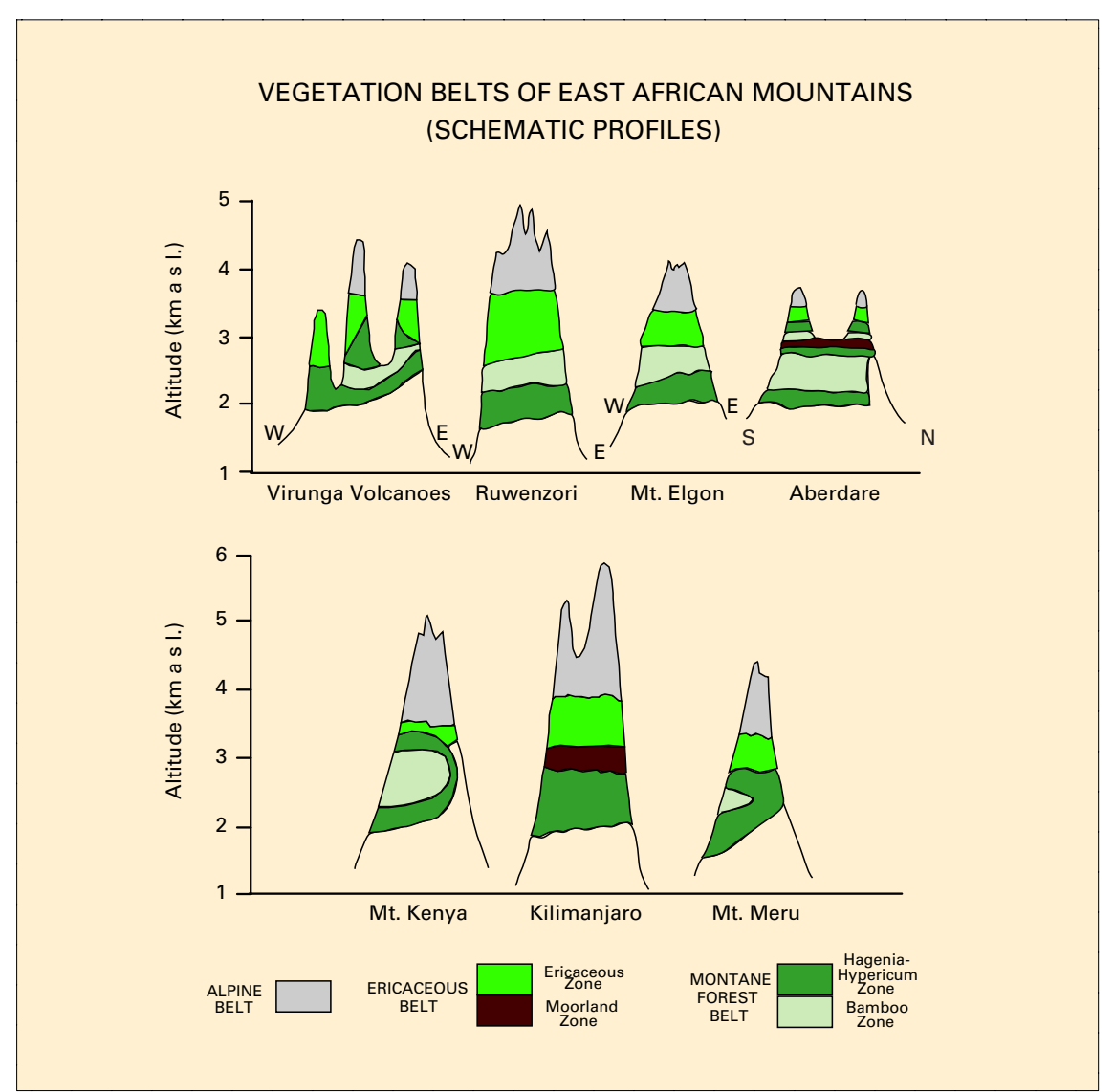

Fig. 2: Schematic profiles of the vegetation belts on East African mountains.

\section{Paleoecology}

The eastern Africa mountains have several swamps and small lakes (crater lakes, tarns) from which sedimentary records of late Quaternary paleoecology have been reconstructed. In this article, we review evidence of the last glacial maximum and Holocene paleoecology of eastern Africa mountains.

The period 22,000 to 14,000 ${ }^{14} \mathrm{C}-\mathrm{yr}$ BP was characterized by expansion of $\mathrm{C}_{4}$ grassland, the fragmentation and depression of high altitude vegetation zones, and progressive aridity (Fig. 3). Although some differences, due to the local or regional climatic factors peculiar to each area, are observed in the precise timing (real or an artefact of age modeling) of vegetation changes between mountains, the shifts were broadly synchronous. These changes are in turn similar to those that occurred simultaneously across the global low latitude belts, suggesting that these environmental changes were driven by globally pervasive climatic factors. Pollenderived estimates of the temperature depression during the Last Glacial Maximum (LGM) for various tropical sites average about $6^{\circ} \mathrm{C}$. More recent temperature estimates, derived from multivariate statistical analysis of pollen assemblages from Kashiru Swamp, and low-altitude Lake Tanganyika, indicate a decrease of $4^{\circ} \mathrm{C} \pm 2^{\circ} \mathrm{C}$ and $4.2 \pm 3.6^{\circ} \mathrm{C}$, respectively. These estimates are generally lower than the earlier inferred LGM-values for East Africa, but are more plausible in view of the uncertainty of both the influence of the large changes in atmospheric $\mathrm{CO}_{2}$ concentrations in tropical vegetation dynamics and the variability of tropical precipitation on seasonal, inter-annual and decadal time-scales. From water balance studies, LGM precipitation is estimated to have been 9 to $32 \%$ lower than present. A recent polleninferred estimate for LGM precipitation decrease relative to present for the central East Africa highlands is $32 \%$ with two maxima at $19,000{ }^{14} \mathrm{C}-y r$ BP (45\%) and 18,000 to $16,000{ }^{14} \mathrm{C}-\mathrm{yr} \mathrm{BP}(42 \%)$. 


\section{Science Highlights}

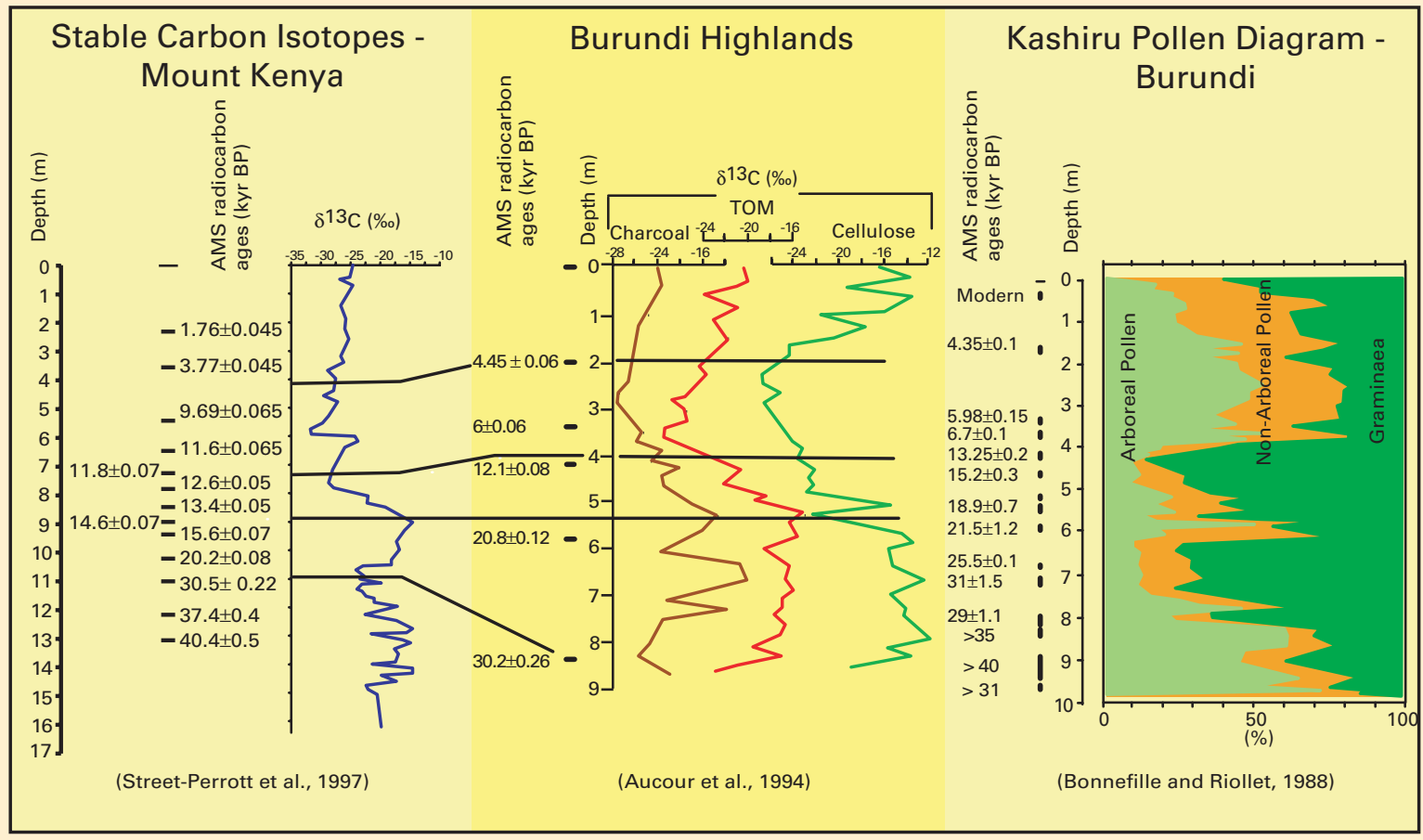

Fig. 3: Profile of glacial-interglacial change from pollen and stable isotope records in east African mountains and highlands.

Pollen, stable carbon isotope data (distinct increase of $\mathrm{C}_{3}$ plants) and morainic evidence show that the period 15,000 to $10,000{ }^{14} \mathrm{C}-\mathrm{yr}$ $\mathrm{BP}$ marked a time of climatic transition, with rising temperatures and an increasingly moist climate. At most sites, increases in $\mathrm{C}_{3}$ plants, marking the onset of warmer, moister climate precede similar evidence from pollen data, and probably reflect a more rapid response of grasses (as compared to woody vegetation) to climatic amelioration. Evidence of a Younger Dryas event is found at some sites, such as on Mount Kenya, between 11,000 and $10,000{ }^{14} \mathrm{C}$-yr BP.

Between 10,000 and $8,000{ }^{14} \mathrm{C}$ yr BP, pollen data indicate a significant expansion of montane forest at high altitude sites occupied by Ericaceous Belt taxa during the last glacial and suggest warmer climate and significantly increased precipitation. Other tropical forests achieved their maximum extension during this period as well. The lake regression phase between 8,000 and $6,000{ }^{14} \mathrm{C}$-yr BP in eastern Africa can be correlated with: 1) relatively cool conditions, depression of the treeline and the establishment of Afroalpine grassland on
Mount Kenya; 2) a shift from evergreen to semi-deciduous forest between 7,000 and 6,000 ${ }^{14} \mathrm{C}-\mathrm{yr}$ BP in the Pilkington Bay area; and 3) an increase in dry tree taxa and Chenoams in the Naivasha area.

Drier conditions in the Holocene were initiated at about $4,000{ }^{14} \mathrm{C}-\mathrm{yr}$ $B P$. This is reflected by replacement of wet montane forest taxa by dry montane forest taxa and a rise in the savanna-forest ecotone at high altitude sites; a shift towards more positive stable carbon isotope values in lake/swamp sediments; and replacement of trees by herbaceous elements at lower altitudes.

Due to their high environmental and climatic sensitivity, mountains offer particularly good sites for highresolution reconstruction of paleoecological change and elucidation of the factors driving the change. High-resolution, multi-proxy analyses of well-dated cores are particularly required from the tropics to better understand the long- and short-term periodicities that characterise the climate and environment of the region. The African region is today very vulnerable to climatic change. Given the rapidity of human impact on the environment, and the associated uncertainties re- garding the impact on global climate and environment, as well as the modes of feedback and degree of interaction between the various components/factors of change, there is a need to better understand the natural climate and environmental variability. More long-term records of change are therefore required to assess the significance of historically documented and modern-day change in the region. For example, the mechanisms underlying the abrupt, large-scale climatic events in the Holocene need to be understood as they occurred during a period with similar climatic conditions as today.

\section{REFERENCES}

Aucour, A., Hillaire-Marcel, L. C. and Bonnefille, R. 1994, Late Quaternary biomass changes from ${ }^{13} \mathrm{C}$ measurements in a highland peatbog from equatorial Africa (Burundi), Quat. Res., 41: 225-233.

Bonnefille, R. and Riollet, G., 1988, The Kashiru pollen sequence (Burundi) paleoclimatic implications for the last 40,000 yr B.P. in Tropical Africa. Quat. Res., 30: 19-35.

Hamilton, A.C., 1972. The interpretation of pollen diagrams from Highland Uganda, Paleoecol. Afr., 7: 45-149.

Street-Perrott, F.A., Huang, Y., Perrott, R.A., Eglinton, G., Barker, P., Khelifa, L., Harkness, D.D. and Olag, D.0., 1997, Impact of lower atmospheric carbon dioxide on tropical mountain ecosystems. Science, Vol. 278, pp.1422-1426. 